\title{
Evaluation of microleakage of RSA Roekoseal Automix root canal sealer
}

Neil Thomas Miller

West Virginia University

Follow this and additional works at: https://researchrepository.wvu.edu/etd

\section{Recommended Citation}

Miller, Neil Thomas, "Evaluation of microleakage of RSA Roekoseal Automix root canal sealer" (2001). Graduate Theses, Dissertations, and Problem Reports. 1258.

https://researchrepository.wvu.edu/etd/1258

This Thesis is protected by copyright and/or related rights. It has been brought to you by the The Research Repository @ WVU with permission from the rights-holder(s). You are free to use this Thesis in any way that is permitted by the copyright and related rights legislation that applies to your use. For other uses you must obtain permission from the rights-holder(s) directly, unless additional rights are indicated by a Creative Commons license in the record and/ or on the work itself. This Thesis has been accepted for inclusion in WVU Graduate Theses, Dissertations, and Problem Reports collection by an authorized administrator of The Research Repository @ WVU. For more information, please contact researchrepository@mail.wvu.edu. 
Evaluation of Microleakage of RSA

Roekoseal Automix Root Canal Sealer.

By

Neil Thomas Miller, DDS

\author{
Thesis submitted to the School of Dentistry \\ of West Virginia University
}

In Partial Fulfillment of the Requirements for

The Degree of

Master of Science

In

Endodontics

C. Russell Jackson, DDS, MS, Chair

Thomas F. Razmus, DDS, MS

Norton P. Smith, DDS, MA

Department of Endodontics

Morgantown, West Virginia

2001

Keywords: RSA Roekoseal Automomix, Roth's 801, Microleakage, Root canal sealer 


\begin{abstract}
Evaluation of Microleakage of RSA Roekoseal Automix Root Canal Sealer
\end{abstract} Neil Thomas Miller, DDS

The sealing ability of RSA Roekoseal Automix root canal sealer using ThermaFil Plus and cold lateral condensation was compared to Roth's 801 root canal sealer. Fiftytwo single canaled roots of extracted teeth were divided into four groups of twelve and instrumented to size 6 with .06 taper series 29 ProFiles. Files were lubricated with RC Prep and canals were irrigated with $5 \% \mathrm{NaOCl}$. Group A canals were obturated with ThermaFil and Roth's 801 sealer. Group B canals were obturated with ThermaFil and RSA Roekoseal Automix. Group C canals were obturated with cold lateral condensation and Roth's 801 sealer. Group D canals were obturated with cold lateral condensation and RSA Roekoseal Automix. Four teeth were used as positive and negative controls. Roots were coated to within $3 \mathrm{~mm}$ of the apex with two layers of fingernail varnish and placed in Higgins ink under $760 \mathrm{~mm} \mathrm{Hg}$ vacuum for three days. The teeth were rendered transparent using a technique described by Roberts. The linear penetration of ink was measured by two observers. A one way ANOVA test was used to analyze the data. There was no significant difference between groups A, C, and D. Group B leaked significantly more than all other groups. RSA RoekoSeal Automix root canal sealer appears to seal as well as Roth's 801 when using cold lateral condensation of gutta percha but not with ThermaFil Plus. 


\title{
ACKNOWLEDGEMENTS
}

\author{
"And whatever you do, do it heartily, as to \\ the Lord and not to men" (Colossians 3:23)
}

First and foremost, I would like to thank my Lord Jesus Christ for the countless blessings he has given me:

For my wife Kathleen. Her love, patients, and support during my dental education have been a constant source of comfort. She has sacrificed time and again so that I could pursue my training.

For my children Nathan, Kristopher, and Erika. They have brought great joy into my life.

For my family. They have encouraged and supported me throughout my life. They were always there for me.

Surely, my cup runneth over.

I would also like to thank Dr. Russell Jackson for the opportunity to become an endodontist. His insight and wisdom have been greatly appreciated. Furthermore, I would like to thank Dr. Norton Smith and Dr. Thomas Razmus for their assistance with this study as members of my committee. Thanks to Dr. Erdogan Gunel for his statistical analysis.

Thanks also to Dr. Robert Raynes, Marilyn Powley, Cathy Myers, and Gina White for their patience and commitment to my development as an endodontist. 
A special thanks to my fellow residents, Dr. Catherine Connor, Dr. Joseph Wateska, Dr. Jason Hales, and Dr. Steve Moore for their support, assistance and camaraderie. 
TABLE OF CONTENTS

PAGE

ACKNOWLEDGEMENTS .......................................ii

TABLE OF CONTENTS ........................................v

LIST OF TABLES ............................................vi

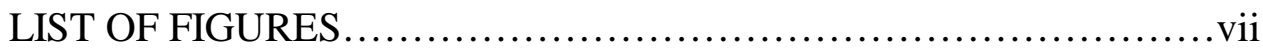

ABSTRACT ................................................ ii

INTRODUCTION $\ldots \ldots \ldots \ldots \ldots \ldots \ldots \ldots \ldots \ldots \ldots \ldots \ldots \ldots \ldots \ldots \ldots \ldots . . \ldots \ldots$

REVIEW OF LITERATURE.....................................

MATERIALS AND METHODS ..................................... 7

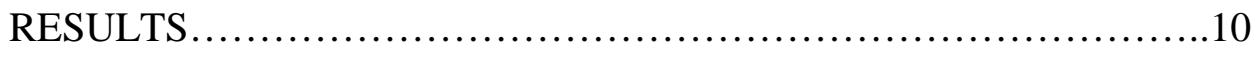

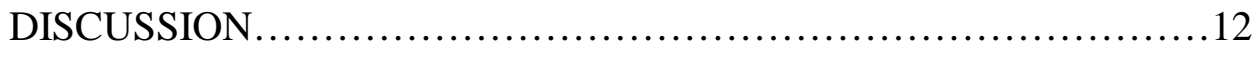

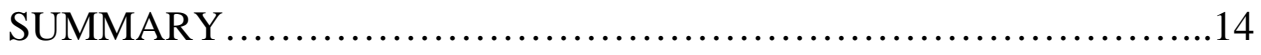

BIBLIOGRAPHY ........................................... 15

APPENDIX A................................................22

VITA.......................................................23 


\section{LIST OF TABLES}

\section{PAGE}

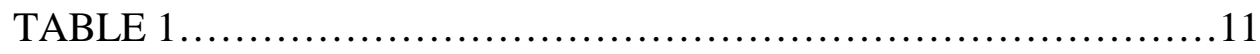

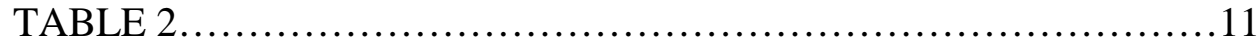


FIGURES

PAGE

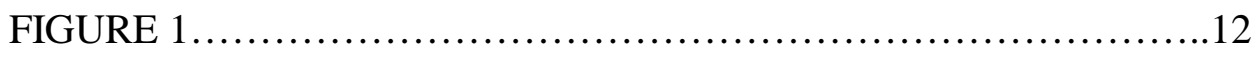




\section{INTRODUCTION}

The ultimate goal of root canal therapy is total obturation of the root canal system. The most common obturation techniques utilize gutta-percha in conjunction with a cementing medium. However, sixty percent of failures in endodontic therapy may be due to inadequate sealing of the root canal system $(1,2,3)$. Thus, over the years many different obturation techniques have been introduced in hopes of increasing the quality of the apical seal. While lateral condensation of gutta-percha is the most widely used method of obturating the root canal system (4), there is evidence indicating that the sealing ability of Thermafil Plus (Dentsply, Tulsa, Oklahoma) is significantly better for sealing curved canals and equal to lateral condensation for sealing canals with curvature less than twenty-five degrees $(5,6)$. Advantages of the Thermafil Plus technique include its predictability, relative ease of use, conservative preparation, and controlled placement of materials. The primary disadvantage is that heated gutta-percha tends to contract as it cools.

Numerous studies have clearly demonstrated that when sealer is used with any obturation technique the apical seal is improved significantly $(9,12,13,14)$. The root canal sealer is used to fill any irregularities or minor discrepancies between the guttapercha filling material and the canal walls. The sealer also acts as a lubricant when placing gutta-percha and may fill any accessory canals or multiple foramina. A wide variety of endodontic sealer cements is available to the profession. Currently, none of the commercially available sealers possess all of the properties required to be considered an 
ideal root canal sealer (42). Therefore, dentistry must continue with research and development of new sealers until the perfect sealer is found.

Recently, Roeko (Langenau, Germany) introduced a new root canal sealer, RSA Roekoseal Automix ${ }^{\circledR}$ which claims to have a "multitude of exceptional features, which makes it the most progressive and outstanding sealer on the market." RSA Roekoseal Automix does have many interesting characteristics, but does this new sealer provide a seal comparable to Roth's 801 (Chicago, Illinois) root canal sealer? The hypothesis is that Roekoseal provides a significantly better seal than Roth's 801 root canal sealer.

This study is designed to investigate the in vitro apical microleakage of RSA Roekoseal Automix root canal sealer used in conjunction with Thermafil Plus and cold lateral condensation versus Roth's $801 \circledR$ sealer when used in conjunction with Thermafil Plus and cold lateral condensation. 


\section{REVIEW OF LITERATURE}

The primary objective of root canal therapy is complete obturation of the root canal system (15). Teeth with severe pulpal involvement are endodontically treated by cleansing and shaping the canal system, followed by total obturation of that space. Once a fluid-tight seal is established, any inflammatory reaction initiated or promoted by noxious material from within the canal should cease. This allows healing of periradicular pathosis. However, if the canal is not completely cleaned and sealed, inflammation and infection may continue. It is believed that percolation of blood borne proteins and/or bacteria cause periapical inflammation due to stagnation and decomposition within the canal space.

Root canal sealers are intended to produce a fluid-tight seal when used alone or in conjunction with a core material such as gutta-percha. In order for a root canal sealer to provide an effective seal it should possess certain characteristics. Grossman (17) identified eleven requirements for the ideal root canal sealer. The root canal cement should: (1) provide an excellent seal when set; (2) produce adequate adhesion between the sealer, the canal walls, and the filling material; (3) be radiopaque; (4) be nonstaining; (5) be dimensionally stable; (6) be easily mixed and introduced into the canals; (7) be easily removed if necessary; (8) be insoluble in tissue fluids; (9) be bactericidal or discourage bacterial growth; (10) be nonirritating to periapical tissue; (11) be slow setting, to ensure sufficient working time. Currently no root canal sealer has been shown to possess all of the ideal properties $(18,19)$. 
There are many root canal sealers including calcium hydroxides, epoxies, resins and zinc oxide and eugenol based, which function adequately in clinical performance. The most popular type of sealer is the zinc oxide and eugenol ( $\mathrm{ZnOE})$ based root canal cement. This type of sealer has a long history of successful use in a clinical setting. One of the more widely used sealers with a ZnOE base is Roth's $801 \circledR$ since it reasonably meets the requirements of the ideal root canal sealer established by Grossman. Weiner and Schilder $(20,21)$ examined the physical properties of a number of root canal sealers and found Roth's $801{ }^{\circledR}$ to have a very slow setting time. This slow setting time is critical in endodontics because it allows time for sealer placement and manipulation during obturation. This study also found Roth's $801 @$ had the least amount of shrinkage of the sealers tested. Grossman (22) studied several physical properties of twelve root canal sealers. The properties examined included flow, setting time, adhesion, and dimensional change (leakage). In comparison to the other sealers, Roth's $801 ®$ was found to have excellent flow capabilities and a slow setting time. Roth's $801{ }^{\circledR}$ also displayed moderate adhesion and very little dimensional change or leakage. At the West Virginia University School of Dentistry, Roth's 801 sealer has been used in endodontic therapy for approximately 30 years. In a retrospective study by Swartz (23), 1,007 teeth receiving root canal therapy at the West Virginia University School of Dentistry were evaluated for success or failure. The success rate for the 1,007 cases was approximately $88 \%$. Because of these factors, Roth's $801{ }^{\circledR}$ sealer is often used as a comparison for newly developed root canal sealers.

Although $\mathrm{ZnOE}$ based root canal sealers such as Roth's $801 \circledR$ have withstood this test of time; dentistry is always looking for materials which will provide more effective 
and predictable results. RSA Roekoseal Automix has many desirable physical, chemical, and biocompatible properties related to dentistry. It is composed of polydimethylsiloxane, silicone oil, paraffin-base oil, hexachloroplatinic acid, and zirconium dioxide. Polymerization is by an addition reaction.

Polydimythylsiloxane/silicone oil has an extremely low surface tension, which provides a high flow rate (44). Polydimethylsiloxane implants prove to be highly biocompatable, eliciting either less or similar tissue response compared to polyethylene when implanted into rats (43). A high flow rate and low film thickness would allow RSA Roekoseal Automix to flow into tiny crevices and tubules. Working time with this sealer is $15-30$ minutes. According to Roeko, RSA Roekoseal Automix is insoluble and has excellent radiopacity. While RSA Roekoseal Automix does not form a chemical bond with dentine, it does expand 0.2 percent on setting. This is in sharp contrast to other sealers, which contract on setting. Initial studies on leakage of root canal filings with RSA Roekoseal Automix were conducted at the University of Erlangen (Germany). The results were presented at the ESE Meeting in Gothenburg 1997 (Sweden). RSA Roekoseal Automix was directly compared to AH 26 (Dentsply, Weybridge, Surrey, England), an epoxy type root canal sealer, and showed significantly less leakage than AH 26. Further tests have been conducted with the results presented at the IADR Meeting in Vancouver 1999. These results showed that the sealing ability of RSA Roekoseal Automix was not affected negatively irrespective of various shaping and filling techniques or the use of different temporary filling materials.

Numerous studies using various techniques have been performed to quantitatively assess the apical leakage potential of root canal filling materials. The main 
techniques used include passive dye penetration $(24,25)$, radioactive isotope penetration $(1,13)$, electrochemical leakage tests $(26,27)$, bacterial penetration $(28,29)$, and scanning electron microscope analysis (30,31). Matloff and coworkers compared several methods of determining apical leakage and found that aqueous solutions of a dye penetrated farther into the canal than any of the isotopes. This would seem to indicate that a dye is a more sensitive indicator of leakage (45). Also, Spalding and Senia demonstrated that entrapped air prevented complete dye penetration in an unfilled, dry canal (37). In a review of the literature there are no studies to date, which specifically compare the apical microleakage of Roekoseal to Roth's root canal sealer. 


\section{MATERIALS AND METHODS}

This in vitro experiment was modeled after a 1993 study by Rodney C. Brown, DDS. Fifty-two single-canaled teeth were obtained from the West Virginia University School of Dentistry. Only teeth with mature apices and type I canal configurations were selected for this study. The teeth were stored in $10 \%$ formalin for varying periods of time. Prior to preparation, the teeth were placed in 5.25\% NaOCL for $24 \mathrm{hrs}$. to dissolve any soft tissue remaining on the root surfaces

In order to minimize experimental variables in the canal preparation and obturation phases, a single operator performed all of the subsequent procedures. The crowns of these teeth were sectioned at the cemental-enamel junction using a high-speed bur and water spray. Working lengths were determined using a \#10 file. One millimeter was subtracted from a length that allowed the tip of the file to reach the apical foramen. The roots were held in a saline-moistened $2 \times 2$ gauze during instrumentation. Apices were machined to a \#15 file $1.0 \mathrm{~mm}$ past the apical foramen. The canal was prepared using a step down technique with .06 taper Profiles. The master apical file (MAF) was a \#6 Profile for each case. To ensure patency of the apical foramen a \#15 K file was passed through the apical foramen after instrumentation was complete. NaOCL 5.25\% was used as the irrigating solution for each specimen with RC Prep (Premier, King of Prussia, Pa.) to provide lubrication and smear layer removal (46).

Fifty-two prepared roots were randomly divided into four groups of 12 roots each and two groups of two each. The groups were filled as follows:

Group A - Thermafil Plus with Roth's 801 
Group B - Thermafil Plus with RSA Roekoseal Automix

Group C - Cold lateral with Roth's 801

Group D - Cold lateral with RSA Roekoseal Automix

Group E - no gutta-percha or sealer and nail varnish covering the entire root

Group F - no gutta percha or sealer and nail varnish covering root within three millimeters of the apex.

The sealers were mixed according to the manufacturer's directions and introduced into the canal using the MAF to coat the canal walls. Then in groups A and B, Thermafil Plus was inserted into the canal to the full working length. For groups $C$ and D, a single .04 taper gutta percha cone, cut to size \#35 was inserted to working length and laterally condensed with size \#25 accessory points. Excess gutta-percha was removed and the gutta-percha in the coronal third of the canal was vertically condensed with a plugger.

Cavit (ESPE America, Inc., Norristown, PA.) was placed in the access cavities and all groups were then stored in a humidor for 7 days with $100 \%$ humidity at room temperature, to allow the sealer to set. The teeth were allowed to air dry and then coated with two layers of nail varnish, except for the apical 2-3 mm. After the nail varnish was completely dry, the teeth were immersed in Higgin's India Ink \#4417 (Bellwood, Illinois) in a vacuum desiccating chamber and placed under a vacuum pressure of 710 torr, where they remained under vacuum for 24 hours. The seal of the vacuum chamber was then broken and the teeth were allowed to passively stain for 4 more days. After immersion, the roots were rinsed with saline and the nail varnish was removed with a scalpel. The roots were then stored in saline to await clearing. 
All teeth were cleared for evaluation using a technique described by Roberts (33). The teeth were placed in 5\% nitric acid for 3 days with daily changes of solution. After rinsing in running tap water for four hours, the roots were dehydrated for 24 hours in $99.8 \%$ ethyl alcohol. Finally, the roots were stored in methyl salicylate to complete the clearing process.

In an attempt to eliminate bias, two evaluators who were unaware of the grouping measured the apical leakage. The roots were viewed using a Ziess Opmi Primo microscope at $7.5 \mathrm{x}$ power. Linear measurements were obtained using a Fowler Caliper with accuracy to 0.001 inches. Linear measurements were made to the nearest 0.001 inch, from the apical terminus of the gutta-percha to the most coronal extent of the India ink penetration. 


\section{RESULTS}

A one way ANOVA test was used to analyze the data.

\section{Inter-rater reliability}

Interclass correlation coefficient of reliability was calculated for all teeth in each of the four groups to check for consistency between the raters. In each case, $r=0.98$ or 0.99 and $\mathrm{p}<0.001$ (see Table 1). This high correlation between raters permitted calculation of an average rating for each tooth.

\section{Leakage}

Group B (ThermaFil + RSA Roekoseal Automix) displayed significantly more leakage than any of the other groups. Mean dye penetration for group B was $1.633 \mathrm{~mm}$. There was no significant difference between any of the other groups. Group A (ThermaFil +Roth's 801) had the lowest mean dye penetration of $0.355 \mathrm{~mm}$. This was followed closely by group D (Cold lateral + RSA Roekoseal Automix) which had a mean dye penetration of $0.380 \mathrm{~mm}$. Group C (Cold lateral + Roth's 801) had a mean dye penetration of $0.699 \mathrm{~mm}$. Table 2 and Figure 1 summarize the mean values for linear dye penetration for groups A through D. Groups E and F were the controls. Group E (nail polish covering the entire root) showed no leakage, while group F (nail polish to within 3 mm of the apex) showed leakage through the entire length of the canal. These results indicate that RSA Roekoseal Automix seals as well as Roth's 801 when using a cold lateral condensation technique. 
TABLE 1: INTERRATER RELIABILITY

\begin{tabular}{|c|c|c|}
\hline GROUP & CORRELATION & P-VALUE \\
\hline $\mathrm{A}$ & .98 & .0001 \\
\hline $\mathrm{B}$ & .99 & .0001 \\
\hline $\mathrm{C}$ & .98 & .0001 \\
\hline $\mathrm{D}$ & .98 & .0001 \\
\hline
\end{tabular}

TABLE 2: MEAN DYE PENETRATION VALUES

\begin{tabular}{|c|c|c|c|}
\hline GROUP & N & MEAN & SD \\
\hline A & 24 & .355 & .413 \\
\hline B & 24 & 1.633 & 1.330 \\
\hline C & 24 & .699 & 1.080 \\
\hline D & 24 & .380 & .456 \\
\hline
\end{tabular}

FIGURE 1: MEAN DYE PENETRATION LENGTH

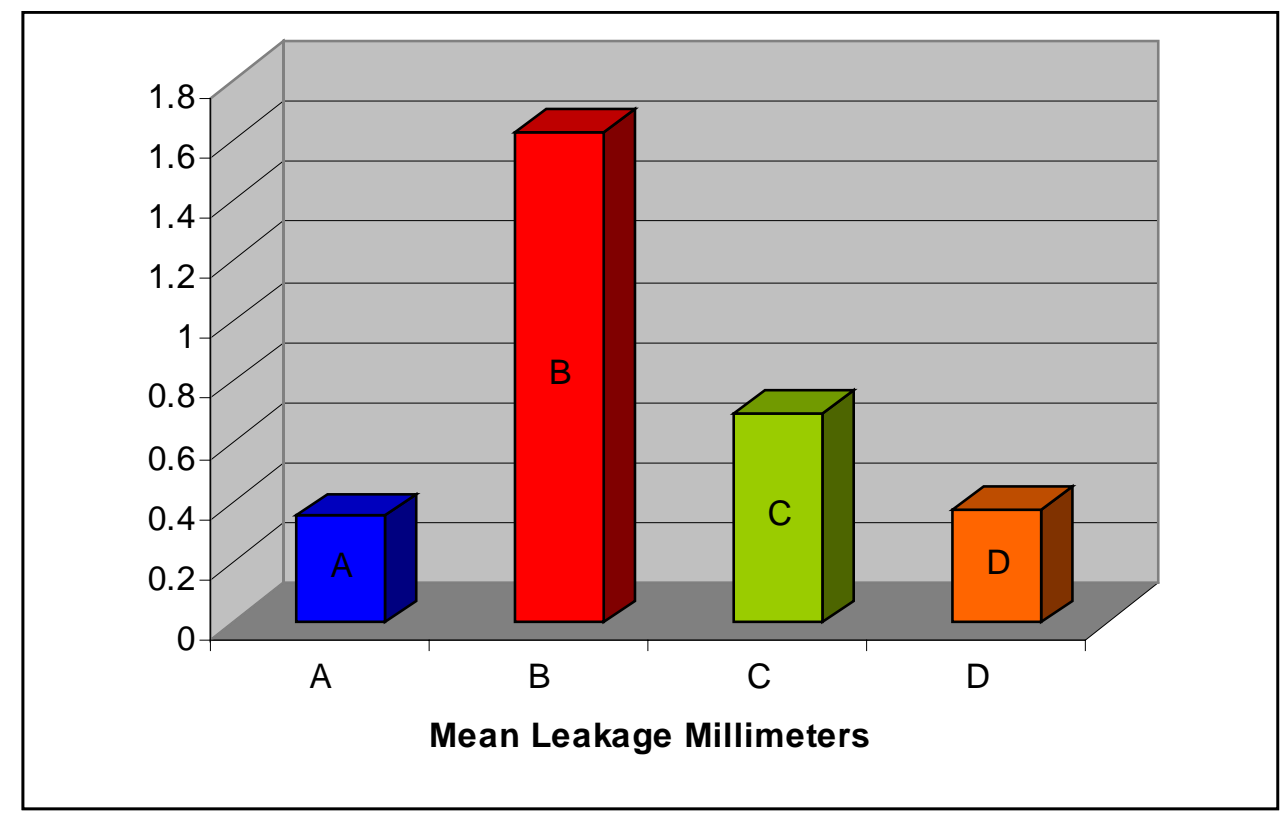




\section{DISCUSSION}

The ultimate objective of root canal treatment is the total obturation of the root canal space (16). In vitro evaluation of new obturation techniques have traditionally included their sealing ability as it compares with laterally condenced gutta-percha. While it is generally accepted that any endodontic filling material or technique that results in the smallest amount of leakage in vitro will be the most preferable material or technique in vivo, there is no sound evidence to support this (11). Therefore, as with any in vitro study, conclusions reguarding any technique or material should not be made without considering the results of several studies.

Results of this study indicate that RSA Roekoseal Automix and Roth's 801 root canal sealer provide a comparable seal when used with cold lateral condensation of gutta percha. When used in conjunction with ThermaFil Plus, RSA Roekoseal Automix was found to leak significantly more than Roth's 801 . These findings differ from the initial research conducted by Gencoglu, et al in Istanbul, Turkey. They found that RSA RoekoSeal Automix sealed significantly better than Grossman's sealer, which is similar to Roth's 801 root canal sealer, when used in conjunction with cold lateral condensation of gutta-percha. Completed in 2000, the Gencoglu, et al study has not yet been published in reputable dental journal. There are no other studies known to exist at this time that evaluate the leakage of RSA RoekoSeal Automix versus Roth's 801 root canal sealer.

It can only be speculated that the differences in the results between this study and the Gencoglu et al study are due to variations in specimens, testing proceedures, and/or operator skill. The difference in leakage when using RSA Roekoseal Automix with 
ThermaFil Plus versus cold lateral condensation could be attributed to the skill of the operator or the possibility that the temperature of the ThermaFil Plus may adversely effect the RSA RoekoSeal Automix. Further research is needed to answer these questions. 


\section{SUMMARY}

The purpose of this study was to investigate the in vitro apical microleakage of RSA Roekoseal Automix root canal sealer versus Roth's 801 root canal sealer when used in conjunction with Thermafil Plus or cold lateral condensation. The results show that RSA Roekoseal Automix seals as well as Roth's 801 root canal sealer when used with cold lateral condensation. However, there was significantly more leakage when RSA Roekoseal Automix was used with Thermafil Plus compared to Roth's 801. Perhaps future studies will determine why RSA Roekoseal Automix does not seal as well when used with Thermafil Plus. 


\section{BIBLIOGRAPHY}

1. Dow, P.R. and Ingle, J.I. Isotope Determination of Root Canal Failure. Oral Surg. $8: 1100-4,1955$

2. Ingle, J.I. and Taintor, J.F. Endodontics. $3^{\text {rd }}$ ed. Philadelphia: Lea \& Febiger, 1985; 36.

3. Weine, F.S. Endodontic Theory. 4th ed. St. Louis: CV Mosby, 1989;13.

4. Walton, R.E. and Torabinejad, M. Principles and Practice of Endodontics. 1st ed. Philadelphia: W.B. Saunders, 1989; 236.

5. Taintor, J.F. and Ross, P.N. Opinions and practices of American endodontic diplomates. Dent. J. 44:321-5, 1978.

6. Rhome, B.H., et al. Isotopic evaluation of the sealing properties of lateral condensation, vertical condensation, and Hydron. J. Endod. 7:458, 1981.

7. Director, R.C., et al. The short-term sealing properties of lateral condensation, vertical condensation and Hydron using 14C human serum albumin. J. Endod. 8:149, 1982.

8. Russin, T.P., et al. Apical seals obtained with laterally condensed, chloroform softened gutta-percha and laterally condensed gutta-percha and Grossman's sealer. J. Endod. 6:678-82, 1980. 
9. Evans, J.T. and Simon, J.H.S. Evaluation of the apical seal produced by injected thermoplasticized gutta-percha in the absence of smear layer and root canal sealer. J. Endod. 12:101, 1986.

10. Haas, S.B., et al. A comparison of four root canal filling techniques. J. Endod. 15:596-601, 1989.

11. Lares, C. and El Deeb, M.E. The sealing ability of the Thermafil obturation technique. J. Endod. 16:474,-9 1990.

12. Skinner, R.L. and Van Himel, T. The sealing ability of injection molded thermoplasticized gutta-percha with and without the use of sealer. J. Endod. 13:315-7, 1987.

13. Marshall, F.J., and Massler, M. Sealing of pulpless teeth evaluated with radioisotopes. J. Dent. Med. 16:172, 1961.

14. Kapsilmalis, P. and Evans, R. Sealing properties of endodontic filling materials using radioactive polar and nonpolar isotopes. Oral Surg. 22:386, 1966.

15. Grossman, L.I. Endodontic Practice. 6th ed. Philadelphia: Lea \& Febiger, 1966. 
16. Schilder, H. Filling canals in three dimensions. Dent. Clin. North Amer. 11:723-44, 1967.

17. Grossman,L., Oliet, S., and Del Rio, C. Endodontic Practice. 1lth ed. Philadelphia: Lea \& Febiger, 1988; 255.

18. Branstetter, J. and von Fraunhofer, J.A. The physical properties and sealing action of endodontic sealer cements: a review of the literature. J. Endod. 8:312-16, 1982.

19. Walton, R.E. and Torabinejad, M. Principles and Practice of Endodontics. 1st ed. Philadelphia: W.B. Saunders, 1989; 234.

20. Wiener, B.H. and Schilder, H. A comparative study of important physical properties of various root canal sealers: evaluation of setting times. Oral Surg. 32(5):76877, 1971.

21. Wiener, B.H. and Schilder, H. A comparative study of important physical properties of various root canal sealers: evaluation of dimensional changes. Oral Surg. 32(6):928-937, 1971.

22 Grossman, L.I. Physical properties of root canal cements. J. Endod. 2:166-175, 1976. 
23. Swartz, D.B., Skidmore, A.E., and Griffin, J.A. Twenty years of endodontic success and failure. J. Endod. 9:198-202, 1983.

24. Massler, M. and Ostrovsky, A. Sealing qualities of various filling materials. J. Dent. Child. 21:228-34, 1954.

25. Grieve, A.R. Sealing properties of cements used in root filling. Br. Dent. J. 132:1922, 1972.

26. Jacobsen, S.M. and von Fraunhofer, J.A. The investigation of microleakage in root canal therapy: an electrochemical technique. Oral Surg. 42:817-23, 1976.

27. Mattison, G.D. and von Fraunhofer, J.A. Electrochemical microleakage study of endodontic sealer cements. Oral Surg. 55:402-7, 1983.

28. Kronman, J.H. et al. Microbiologic evaluation of poly-HEMA root canal filling material. Oral Surg. 48:175-7, 1979.

29. Kos, W.L., Aulozzi, D.P., and Gerstein, H. A comparative bacterial microleakage study of retrofilling materials. J. Endod. 8:355-8, 1982.

30. Torabinejad, M. et al. Scanning electron microscopic study of root canal obturation using thermoplasticized gutta-percha. J. Endod. 4:245-50, 1,978. 
31. Lugassy, A.A. and Yee, F. Root canal obturation with gutta-percha: A scanning electron microscopic comparison of vertical compaction and automated thermatic condensation. J. Endod. 8:120-5, 1982

32. Weine, F.S. Endodontic Therapy. 4th ed. St. Louis: CV Mosby, 1989; 222-223.

33. Roberts, D. et al. A clearing technique for the study of root canal systems. J. Endod. 6:421-24, 1980

34. Smith, M.A. An in vitro evaluation of microleakage of two new root canal sealers. Presented at the Ohio Assoc. of Endodontists, May 1992.

35. Mitchem, J. and Gronas, D. Adhesion to dentin with and without smear layers under varying degrees of wetness. J Dent. Res. 68:321, 1989.

36. Spangberg, L.W., Acierno, T.G., and Cha, B.Y. Influence of entrapped air on the accuracy of leakage studies using dye penetration methods. J. Endod. 15:54851, 1989.

37. Goldman, M., Simmonds, S., and Rush, R. The usefulness of dye-penetration studies re-examined. Oral Surg. Oral Med. Oral Pathol. 67:327-32, 1989.

38. Allison, D.A., Weber, C.R., and Walton, R.E. The influence of the method of canal preparation on the quality of apical and coronal obturation. J. Endod. 5:298304, 1978. 
39. Friedman, S., Moshonov, J., and Trope, M. Efficacy of removing glass ionomer cement, zinc oxide eugenol, and epoxy resin sealers from retreated root canals. Oral Surg. Oral Med. Oral Pathol. 73:609-12, 1992.

40. Leung, S. F., Gulabivala, K. An in-vitro evaluation of the influence of canal curvature on the sealing ability of Thermafil. Int Endod J. 190-196, July 1994.

41. Saunder, W. P., Saunders, E. M. Influence of smear layer on the coronal leakage of Thermafil and laterally condensed gutta-percha root fillings with a glass ionomer sealer. J Endod. 155-158, April 1994.

42. Caicedo,R.,von Fraunhofer, J. A. The Properties of Endodontic Sealer Cements. J Endod. 527-534, Nov. 1988.

43. Sherman, M. A., Kennedy, J. P., Ely, D. L., Smith, D. Novel Polyisobutylene/Polydimethylsiloxane Biocomponent Networks: III. Tissue Compatibility. J Biomater Sci Polym Ed 1999; 10(3):259-269.

44. Rolla, G., Ellingsen, J. E., Gaare, D. Polydimethylsiloxane as a Tooth SurfaceBound Carrier of Triclosan: A New Concept in Chemical Plaque Inhibition. Adv Dent Res 1994 Jul;8(2):272-277. 
45. Matloff, I. R., Jensen, J. R., Singer, L., Tabibi, A. A Comparison of Methods Used in Root Canal Sealability Studies. Oral Surg. Oral Med. Oral Path. 1982; 53: 203-8.

46. Stewart, G. G. A Scanning Electron Microscopic Study of the Cleansing Effectiveness of Three Irrigating Modalities on the Tubular Structure of Dentin. J. Endon. 1998 Jul; 24(7): 485-6. 


\section{APPENDIX A}

RATER \#1 (INCHES)

\begin{tabular}{|c|c|c|c|c|c|}
\hline Group A & Group B & Group C & Group D & Group E & Group F \\
\hline 0 & .085 & .139 & 0 & No Leakage & Total Leakage \\
\hline 0 & 0 & 0 & 0 & No Leakage & Total Leakage \\
\hline .038 & 0 & 0 & .036 & & \\
\hline .036 & 0 & 0 & 0 & & \\
\hline .027 & .124 & .025 & .030 & & \\
\hline .021 & .107 & 0 & .012 & & \\
\hline .007 & .069 & .084 & 0 & & \\
\hline 0 & .136 & .059 & .019 & & \\
\hline 0 & .109 & 0 & 0 & & \\
\hline 0 & 0 & .029 & .032 & & \\
\hline .037 & .060 & 0 & .052 & & \\
\hline 0 & .061 & 0 & 0 & & \\
\hline
\end{tabular}

RATER \#2 (INCHES)

\begin{tabular}{|c|c|c|c|c|c|}
\hline Group A & Group B & Group C & Group D & Group E & Group F \\
\hline 0 & .085 & .132 & 0 & No Leakage & Total Leakage \\
\hline 0 & 0 & .013 & 0 & No Leakage & Total Leakage \\
\hline .038 & 0 & 0 & .040 & & \\
\hline .028 & 0 & .004 & 0 & & \\
\hline .029 & .130 & .007 & .031 & & \\
\hline .027 & .111 & 0 & .012 & & \\
\hline .008 & .075 & .075 & 0 & & \\
\hline 0 & .150 & .065 & .016 & & \\
\hline 0 & .115 & 0 & 0 & & \\
\hline 0 & 0 & .028 & .028 & & \\
\hline .040 & .059 & 0 & .051 & & \\
\hline 0 & .067 & 0 & 0 & & \\
\hline
\end{tabular}




\section{CURRICULUM VITAE}

\section{Biographical Data}

Name:

Neil Thomas Miller

Date of Birth:

May 18, 1971

Place of Birth:

Salem, Ohio

Spouse:

Kathleen Sue Miller

Children:

Nathan, Kristopher, and Erika

\section{Education}

1989-1991 West Virginia University

No Degree

1991-1995

West Virginia University

DDS

1999-2001

West Virginia University

MS, Certificate

\section{Employment}

1995-1995 West Virginia University

Oral Diagnosis Fellowship

1995-1999 Naval Dental Officer

Camp Lejune, NC

Great Lakes, IL

1999-2001 West Viginia University

Endodontics Residency 